\title{
Por um babelismo ético na educação: reflexões acerca das implicações e possibilidades de se proceder à ética coconstitutiva dos modos de se fazer pesquisa
}

\author{
Towards an ethical babelism in education: reflections on the implications and \\ possibilities of the co-constitutive ethics of ways of doing research
}

Por un babelismo ético en la educación: reflexiones acerca de las implicaciones y posibilidades de proceder a la ética coconstitutiva de los modos de hacer investigación

\author{
LUÍS HENRIQUE SACCHI DOS SANTOS*
}

\begin{abstract}
RESUMO
O texto apresenta alguns dos caminhos que precederam a publicação da Resolução 510/16 do Conselho Nacional de Saúde, situa a recorrente cisão entre as matrizes de conhecimento das Ciências Humanas e Sociais (CHS) e das Ciências de origem "Bio", especialmente no que tange à centralidade da bioética como "modelo" de ética para as CHS, bem como problematiza a ética regulamentadora (baseada nas Resoluções 466/12 e 510/16) em relação às éticas "intrínsecas" de cada campo de pesquisa. A partir disso, lança algumas perguntas que visam a constituir um caminho ético-metodológico e político em direção a uma ética coconstitutiva dos modos de se fazer pesquisa. Tece também algumas críticas ao modelo ético universalizante, no qual a ética passa também a ser uma commodity, ou mais um produto a ser consumido no atual mercado da ciência e da produção de biovalor.
\end{abstract}

Palavras-chave: Ética. Pesquisa em educação. Sistema CEP/Conep.

\begin{abstract}
The text presents some of the paths that preceded the publication of Resolution 510/16 of the National Health Council. It places the recurring split between the knowledge matrices of the Human and Social Sciences (HSC) and the sciences of "Bio" origin, specially the centrality of bioethics as a "model" of ethics for the HSC. The text also problematizes the regulatory ethics (based on Resolutions 466/12 and 510/16) in relation to the "intrinsic" ethics of each field of research. From this, it poses some questions that seek to constitute an ethical-methodological and political path towards a co-constitutive ethics of the ways of doing research. It criticizes the universalizing ethical model, in which ethics also become a commodity, or another product to be consumed in the current market of science and biovalor production.
\end{abstract}

Keywords: Ethics. Research in education. CEP/Conep system.

\section{RESUMEN}

El texto presenta algunos de los caminos que precedieron a la publicación de la Resolución 510/16 del Consejo Nacional de Salud, sitúa a la recurrente escisión entre las matrices de conocimiento de las Ciencias Humanas y Sociales (CHS) y de las Ciencias de origen "Bio", especialmente en lo que dice respecto a la centralidad de la bioética como "modelo" de ética para las CHS, así como problematiza la ética reguladora (basada en las Resoluciones 466/12 y 510/16) en relación a las éticas "intrínsecas" de cada campo de investigación. A partir de eso, lanza algunas preguntas que apuntan para la constitución de un camino ético-metodológico y político hacia una ética coconstitutiva de los modos de hacer investigación. Tece también algunas críticas al modelo ético universalizante, en el cual la ética pasa también a ser un commodity, o un producto que se consume en el actual mercado de la ciencia y de la producción de biovalor.

Palabras clave: Ética. Investigación en educación. Sistema CEP/Conep.

\footnotetext{
* Professor Associado no Departamento de Ensino e Currículo da Faculdade de Educação da Universidade Federal do Rio Grande do Sul (UFRGS). Faculdade de Educação/Programa de Pós-Graduação em Educação/UFRGS. Membro do Comitê de Ética em Pesquisa da UFRGS (2014-2017).E-mail: <luishss2009@ gmail.com > $\mathrm{O}$ autor agradece às críticas e sugestões feitas pelas professoras Daniela Ripoll, Fabiana de Amorim Marcello e Iara Tatiana Bonin
} 


\section{INTRODUÇÃO}

Nas diferentes oportunidades em que se fala acerca da "nova resolução" para as Ciências Humanas e Sociais (CHS) - a Resolução 510, de 7 de abril de 2016 -, diz-se que, se ela não é ou não representa os anseios que os diferentes segmentos dessas áreas requereram ao longo do período em que o debate acerca de sua instituição se estabeleceu, ela é aquilo que se pode ter neste momento. Debate esse notadamente constituído a partir da publicação da Resolução 466/12, em 2012, que já indicava a necessidade de uma resolução complementar para as Ciências Humanas e Sociais. Aprovada pelo Conselho Nacional de Saúde, a Resolução 510/16, em seu artigo primeiro, "dispõe sobre as normas aplicáveis a pesquisas em Ciências Humanas e Sociais cujos procedimentos metodológicos envolvam a utilização de dados diretamente obtidos com os participantes ou de informações identificáveis ou que possam acarretar riscos maiores do que os existentes na vida cotidiana".

É notório, através das diferentes comunicações encaminhadas pelas instituições representativas, tal como a própria Associação Nacional de Pesquisa e PósGraduação em Educação (Anped) ${ }^{1}$, que se travou uma luta entre o Grupo de Trabalho de Ciências Humanas e Sociais (GT-CHS) e a própria Comissão Nacional de Ética em Pesquisa (Conep) ${ }^{2}$, a qual levou a um adiamento e a alguns impasses ${ }^{3}$ na promulgação da Resolução 510/16. Apesar disso (e das possíveis questões de ordem interna à própria Conep, as quais não são analisadas no presente texto), mesmo em tom especulativo, ressalta-se que isso se deu, também, por uma questão ético-política conjuntural e contingente que talvez represente a manutenção de um tipo de ética protetiva do próprio sistema CEP-Conep e dos direitos aos cidadãos brasileiros. Isso porque não foi possível às áreas das CHS terem uma resolução diferente ou próxima àquela "dos sonhos" e que envolveria, inclusive, a proposição de criação de outro sistema de

\footnotetext{
1 Foi a partir de 2013 que a Anped passou a ter representação no GT da Conep, encarregado de elaborar uma resolução complementar à Resolução 466/2012, de forma a atender às especificidades das áreas de Ciências Sociais e Humanas (vide < http://www.anped.org.br/site/eticana-pesquisa >; <http://www.anped.org.br/news/sobre-o-gt-de-cienciassociais-e-humanas-na-conep $>$, acessados em: 23 nov. 2016).

2 A Conep, uma comissão do Conselho Nacional de Saúde (CNS), foi criada através da Resolução 196/96, que foi a primeira a instituir as diretrizes para a ética e pesquisa com seres humanos no Brasil.

3 A consulta pública em torno da minuta do que veio a ser a Resolução 510/16 encerrou-se no início do segundo semestre de 2015, e previa-se a sua publicação ainda antes do término daquele ano. No entanto, após alguns impasses em relação ao teor da própria resolução, que incluiu a própria retirada do GT de uma das reuniões no âmbito da Conep, a resolução veio a ser aprovada em 7 de abril de 2016 (vide < http:// www.anped.org.br/site/etica-na-pesquisa/news $>$, acessado em: 23 nov. 2016).
}

avaliação ético, alocado nos Ministérios da Educação ou da Ciência e Tecnologia ${ }^{4}$.

$\mathrm{O}$ argumento aqui defendido é consubstanciado por um breve (mas importante) conjunto de análises ${ }^{5}$ que atesta que o próprio sistema CEP-Conep se encontra ameaçado por uma política de retrocesso $\left(\right.$ backlash $\left.^{6}\right)-$ de matriz neoliberal, que visa, no caso em questão, sobretudo, à retirada de alguns dos direitos éticos dos participantes de pesquisa no Brasil (como a obrigatoriedade de manter o tratamento de forma gratuita, caso o medicamento se mostre eficaz, por tempo indeterminado). Apesar dos impasses e das controvérsias, o Projeto de Lei (PLS) no $200 / 2015^{7}$ foi aprovado em caráter terminativo,

${ }^{4}$ Convém destacar que o próprio Ministério da Ciência, Tecnologia e Inovação foi, após o impeachment/golpe de 2016, fusionado ao Ministério das Comunicações, o que foi muito contestado pela Sociedade Brasileira para o Progresso da Ciência (SBPC), uma das mais importantes associações científicas dos país (ver $<$ https://tecnoblog. net/195461/gilberto-kassab-ministro-ciencia-tecnologia-comunicacoesquem/>; <http://www.sbpcnet.org.br/site/noticias/materias/detalhe. php?id=5077>; <http://www.mcti.gov.br/>, acessados em: 30 jan. 2017).

5 Ver, por exemplo, notas da Conep ( $<$ http://www.anped.org.br/site/etica-napesquisa/news >; <http://conselho.saude.gov.br/web_comissoes/conep/ Noticias/2016/07jul05 conep analisa substitutivo PL200.html>, bem como os vídeos $<$ https://www.youtube.com/watch? $=$ veloodw96K93U>; $<\mathrm{https}: / /$ www.youtube.com/watch?v=vBaQFS jSRo $>$; <https://www. youtube.com/watch? $\mathrm{v}=0 \mathrm{aCkqvsnGRU}>\mathrm{e}<\mathrm{http}: / /$ globosatplay.globo. com/globonews/v/4552502/>, entre outros, acessados em: 15 jan. 2017) referentes ao projeto de lei que modifica a legislação sobre pesquisas clínicas com seres humanos.

${ }^{6} \mathrm{O}$ conceito de backlash, como uma política de antagonismo ou uma reação conservadora, foi apresentado pela jornalista Susan Faludi no livro Backlash: o contra-ataque na guerra não declarada contra as mulheres, publicado em 1991, nos Estados Unidos (e em 2001, pela Editora Rocco, no Brasil). O conceito faz referência, sobretudo, à reação conservadora (configurado como um ataque conservador) que o movimento feminista (ou, para ser mais claro, as mulheres) sofreu por parte das mídias norteamericanas, que enfatizavam que a busca feminina por igualdade era o motivo para a angústia das mulheres americanas nos anos 1980. Como refere Cely Couto (em <https://cafefeminista.wordpress.com/2013/07/14/ backlash-desvendando-o-contra-ataque-antifeminista/>, acessado em 14/01/2017), "convém explicar que o backlash não é uma conspiração, como um conselho secreto emanando ordens para destruir as feministas. Muitas vezes, as pessoas envolvidas na onda [conservadora] não estão conscientes de seus papéis, ou até se consideram defensoras das mulheres. Seria até mais fácil culpar uma 'elite' ou um grupo de pessoas pelos esforços em combater as conquistas femininas, mas trata-se de algo maior, um fenômeno que revela o medo generalizado da transformação social". Mais recentemente, em outra direção, mas, pode-se dizer, em convergência com esse conceito apresentado por Faludi, Arjun Appadurai lançou o livro $\mathbf{O}$ medo ao pequeno número - ensaio sobre a geografia da raiva (2009), no qual descreve como o medo às minorias geográficas e religiosas, por exemplo, têm, igualmente, deflagrado uma série de medidas conservadoras e de ataque. É, portanto, a ideia de um conservadorismo ou, mais exatamente, de um retrocesso, associada a uma matriz econômica neoliberal (em linhas gerais, de retração de direitos), que advoga em favor de benefícios ao mercado (à livre concorrência e circulação do capital - vide, por exemplo, a fala do presidente executivo da Interfarma, Antônio Britto, no link: <http://www.jornaldaciencia org.br/edicoes/?url=http://jcnoticias.jornaldaciencia.org.br/1-propostaaprovada-no-senado-permite-brasil-criar-1o-marco-legal-das-pesquisasclinicas/>, acessado em 21/12/2016). Enfatiza-se ser esta uma política do retrocesso/backlash em detrimento dos direitos humanos - mesmo de modo provisório, mas ciente de sua melhor articulação no futuro.

7 O Projeto de Lei do Senado no 200, de 2015, de autoria dos senadores Ana Amélia Lemos, Waldemir Moka, Walter Pinheiro e outros, dispõe sobre princípios, diretrizes e regras para a condução de pesquisas clínicas em seres humanos por instituições públicas ou privadas (vide 
em 14 de dezembro de 2016, na Comissão de Assuntos Sociais (CAS), do Senado Federal, e segue, agora, para o crivo da Câmara dos Deputados, onde deve ser aprovado neste ano de $2017^{8}$.

Assim, a despeito do caráter legítimo requerido pelas CHS, de retirar a avaliação ética de uma matriz bioética principialista $^{9}$, supostamente universal (assentada no sistema CEP-Conep, alocado no Ministério da Saúde), ceder aos anseios das CHS, neste momento, em termos ético-políticos, talvez significasse perder a "queda de braço" com a política do retrocesso em termos bioéticos. Esta representada pela ameaça que a tramitação da PL-200 traz para a população brasileira, em especial para aqueles/as que, mais imediatamente, participam de pesquisas clínicas no Brasil. Nessa direção, a manutenção do sistema CEP/Conep e as lutas políticas que se travaram em torno da 510/16 talvez sejam estratégicas, neste momento, para o não enfraquecimento estrutural diante de uma ameaça muito mais ampla aos direitos éticos da população do que a possibilidade de ter, tal como requeria (ou requer) as CHS: a instituição de uma avaliação ética assentada na tradição de se fazer pesquisas em CHS no Brasil.

Politicamente, talvez se deva pensar e operar na direção de se entender que não cindir o sistema CEPConep, mesmo quando assentado na racionalidade de matriz bioética principialista do campo da saúde, pode vir a representar uma medida protetiva - mesmo que momentânea, num momento de retrocesso políticosocial. Isso não significa, contudo, que não se deva continuar produzindo argumentos, tanto na direção do esclarecimento e da participação (através de medidas educativas e de incentivo à participação no controle social) da população mais ampla quanto academicamente. No sentido de construir as bases para um possível deslocamento da racionalidade da matriz bioética principialista para outra mais condizente com as práticas e tradições no campo das CHS, notadamente, no caso do presente texto, da Educação. Em outras palavras -

$<$ http://www25.senado.leg.br/web/atividade/materias/-/materia/ 120560>, acessado em 23/11/2016). Representa, segundo esclarecimentos do Dr. Jorge Venâncio, coordenador da Conep, no programa "Entre Aspas", da GloboNews, apresentado em 20/10/2015 (vide <http://conselho.saude. gov.br/web comissoes/conep/index.html >, acessado em 23/11/2016), os anseios da Associação da Indústria Farmacêutica de Pesquisa (Interfarma). Esta, criada em 1990 e presidida pelo ex-governador do Rio Grande do Sul, o jornalista Antônio Britto, "representa 56 laboratórios estrangeiros que, hoje, são responsáveis pela venda de $80 \%$ dos medicamentos de referência e por $33 \%$ dos genéricos disponíveis no mercado brasileiro" (vide <http://www.cartacapital.com.br/blogs/outras-palavras/o-lobby-ea-industria-farmaceutica-no-brasil >, publicado em 22/08/2016 e acessado em 23/11/2016)

8 Vide $<$ http://www.jornaldaciencia.org.br/edicoes/?url=http://jcnoticias. jornaldaciencia.org.br/1-proposta-aprovada-no-senado-permite-brasilcriar-1o-marco-legal-das-pesquisas-clinicas/>, acessado em 21/12/2016.

9 Caracterizado pelos princípios da autonomia, beneficência, não maleficência e justiça. e para empregar um jargão popular -, talvez a 510/16 represente um "mal necessário", através do qual se possa vir a aprender a produzir outras formas, política e academicamente consistentes, para a futura construção de outros princípios éticos.

\section{POR UMA ÉTICA BABÉLICA}

A ideia de Babel, de uma ética babélica (ver SANTOS e KARNOPP, 2017), ou seja, da possibilidade (e da necessidade) de se falar diferentes línguas (e de se aprender a entender diferentes línguas), na contramão de uma suposta universalidade (de um monolinguismo bioético), é o que tem provocado tensionamentos no que tange à instituição da 510/16. Não se quer refutá-la como regramento ético contemporâneo, mas, sim, poder estabelecer um diálogo possível no presente, em direção a produzir novos diálogos, traduções e, quiçá, novas linguagens no futuro. Isso porque, tal como expressam Larrosa e Skliar (2001),

Babel fala de unanimidade, de totalidade e de mesmidade: de uma cidade, de uma torre, de um nome e de uma língua, que são para todos a mesma coisa. E fala também do fim da unanimidade, da totalidade e da mesmidade: da dispersão de homens, da destruição da torre, da perda do nome, da confusão da língua e do aparecimento de outros homens, de outras torres, de outros nomes e outras línguas (p. 10).

E, ainda a partir desses autores (LARRROSA e SKLIAR, 2001), se é o nome confuso e incompreensível de Babel o que melhor nomeia a presente condição (em um mundo cada vez mais globalizado e onde as "coisas" precisam circular livremente para serem consumidas), "outra vez nos pensamos como babilônios, como habitantes de Babel, e também babélicos alguns dos temas que nos obsessionam" (idem, p. 8). Essa condição é também confusa e incompreensível no embate entre a ética regulamentadora estabelecida (e sua pretensa vontade de universalidade) e as tradições construídas nos próprios fazeres ético-político-metodológicos das CHS, e da Educação em particular (com suas diferentes histórias). Uma ética regulamentadora em pesquisa e em seus anseios, por assim dizer, direcionada a unificar procedimentos e princípios de pesquisa que já "nasceram" e se estabeleceram como diferentes (embora convergentes e intercambiáveis em algumas direções) ao longo do século XX. Como bem referem esses autores, parece que se deve aprender:

(...) a viver juntos e a comunicar-se ordenadamente Tem-se a impressão de que se deve conjurar os perigos de Babel e voltar a reunir os homens, não agora em 
torno de uma cidade, de uma torre, de um nome e de uma língua, mas a partir da diversidade bem ordenada e bem comunicada de diferentes cidades, diferentes torres, diferentes nomes e diferentes línguas. Tem-se a impressão de que a questão é administrar as diferenças, identificando-as, e tratar de integrar todos em um mundo inofensivamente plural e ao mesmo tempo burocrática e economicamente globalizado (...) (idem, p. 11-12).

A partir dos aportes críticos de Larrosa e Skliar (2001), enfatiza-se que a ética ou, mais exatamente, as éticas não são uma condição essencial das formas de se produzir conhecimento e de se "consumir produtos da ciência" no mundo contemporâneo, mas uma produção de um dado tempo. Antes, parafraseando Latour (ao dizer que "a ciência é a política por outros meios"), a ética - pode-se arriscar - também é política e, como tal, dá-se por outros meios. Como refere o autor, a ciência é como um peixe - e sabe-se o que acontece com os peixes quando ficam fora da geladeira! Em termos éticos, se forem revisadas muitas das práticas de pesquisa - seja através de um crivo interno das práticas de pesquisa já instituídas, seja através do cotejamento com o regramento ético proposto -, talvez se encontre uma série de "inconsistências éticas" nos fazeres cotidianos, tidos, por vezes, como "naturais" dos campos de pesquisa. Assim, mesmo resistentes aos regramentos éticos, talvez se deva demorar um pouco mais naquilo que usualmente se considera como práticas instituídas e se deva também, a partir disso, refletir e problematizar os fazeres em pesquisa na direção de um outro possível patamar. Aqui, a pergunta talvez pudesse ser assim formulada: o que se tem a oferecer em termos de "universalidades" à suposta universalidade da ética principialista, a qual, segundo se discute adiante, "serve" bastante bem aos propósitos do consumo rápido e supostamente adequado às necessidades de circulação da ciência contemporânea? Em outras palavras, como podem as CHS virem a contribuir para a proposição de outra(s) ética(s), tendo em vista as especificidades de cada área?

Tais perguntas são procedentes precisamente porque, tal como se sabe,

nos últimos duzentos anos, vivemos uma separação entre natureza e cultura que, grosseiramente, marcou os limites entre as ciências biológicas e 'exatas', por um lado, e humanas, por outro. Essas fronteiras nunca foram pacíficas, movendo-se ao sabor de escaramuças intermináveis - mas, em linhas gerais, funcionaram (RIBEIRO, 2003, p. 15).

Ainda seguindo Ribeiro (2003), é possível dizer que as ciências da natureza tratam a natureza, o mundo em geral e também o homem (ou o humano) como objeto; enquanto as ciências humanas partem do escândalo que éo ser humano conhecer a si próprio (o homem como sujeito cognoscente e como alvo desse mesmo conhecimento), misturando as posições de sujeito e objeto. Isso, segundo ele, formula sérios problemas, tornando quase impossível a objetividade, que é o critério básico da ciência desde o século XVII. Para ser ainda mais claro em relação à pergunta acerca da suposta universalidade dos princípios éticos, "a recusa da separação entre sujeito e objeto é o que constitui as ciências humanas ${ }^{10}$ " (RIBEIRO, 2001, p. 17). Indaga-se: como ousar em direção a algum caminho que não proponha objetividade e universalidade, mas, antes, especificidades construídas ao longo do tempo de constituição de cada disciplina ou campo de conhecimento? Assim, quando se instaura o debate sobre ética em pesquisa, especialmente quando as propostas de resoluções (tal como a 466/12 e a 510/16) visam a normatizar os fazeres de pesquisa instituídos a partir de dados princípios, supostamente universais, reavivam-se os "velhos babelismos" que caracterizam a separação entre as hard e as soft sciences.

\section{DE QUE ÉTICA SE ESTÁ FALANDO? COMO CONCILIAR?}

\section{Ética "coconstitutiva" aos modos de fazer pesquisa}

É fato que agora se conta com um conjunto de princípios éticos propostos pela ética regulamentadora, cujo trâmite pode ser sucintamente expresso: sistemas de pesquisa nas universidades $\rightarrow$ Plataforma Brasil $\rightarrow$ Comitês de Ética em Pesquisa (CEP)/Comissão Nacional de Ética em Pesquisa (Conep). Mas se tem também um conjunto de questões de ordem ética que não estão "apenas" regulamentadas pelo sistema CEP/Conep. Nas CHS, pode-se dizer que muitos vêm argumentando que a(s) ética(s) nesses campos de atuação seria(m) intrínseca(s) aos próprios modos de se fazer pesquisa, os quais têm norteado e orientado, ao longo do tempo, a formação de novos pesquisadores nas disciplinas. Em outras palavras, argumenta-se que ética se aprenderia fazendo a própria pesquisa, "sentindo" o campo, as pessoas e as situações; estabelecendo-se no caso a caso. Sem dúvidas, muitas dessas ações são "intrinsicamente" éticas, mas outras, mesmo quando consideradas éticas, poderiam vir a ser questionadas à luz de alguns dos princípios mais elementares daquilo que consta nas atuais regulamentações acerca de ética em pesquisa no Brasil. Um exemplo frequentemente comum no campo da educação é a "dupla-função", por assim dizer, que

\footnotetext{
${ }^{10}$ Ver As palavras e as coisas, de Michel Foucault, ou, para uma perspectiva "reconciliatória", ver Rose (2013).
} 
muitos professores, estudantes de mestrado ou de doutorado, exercem ao utilizarem suas próprias aulas (do ensino fundamental ao universitário) como campo de pesquisa para suas dissertações e teses. Essa "duplafunção", mesmo quando atendendo aos princípios éticos normativos (como solicitação de termo de consentimento livre e informado e/ou termo de assentimento), pode contribuir para aumentar a assimetria entre participantepesquisador. Isso porque a função de professor já estabelece, de antemão, uma relação hierárquica entre aluno-professor, a qual, se não for devidamente cuidada, pode atuar de maneira coercitiva em relação à participação na pesquisa (e não livre, como pressupõem os princípios éticos de pesquisa).

Ressalta-se que, mesmo quando se opera a partir de uma ética regulamentadora (que visa a tornar todos os princípios de pesquisa literalmente "achatados" a partir de um possível fazer padronizado), precisa-se acionar um conjunto de práticas desenvolvidas em cada campo, porque, embora as resoluções sirvam para orientar e regular a pesquisa, lidar apenas com seus princípios não garante uma pesquisa "intrinsicamente" ética. Nesse sentido, também se argumenta na direção daquilo que se chama ética coconstitutiva aos modos de fazer pesquisa, a qual pressupõe que as questões de ordem ética em qualquer projeto de pesquisa não se encontram apenas na seção do projeto em que se descrevem os procedimentos metodológicos e as considerações de ordem ética. Antes, constituem-se a partir da própria história da perspectiva teórica (ou do campo de pesquisa) na qual se está inserido, dos tipos de perguntas que se fazem com base nisso, bem como dos tipos de abordagens ou métodos metodológicos que se escolhem para empreender uma pesquisa. E, ainda, por meio da elaboração das análises, da publicação dos dados e da sua devolução aos participantes da pesquisa e à sociedade em geral. Este talvez seja o aspecto (pedagógico) mais produtivo de se pensar em relação ao debate que vem se estabelecendo, na forma de resistência (e também acomodação) à Resolução 466/12 e, sobretudo, à 510/16, supostamente a resolução das CHS.

A pergunta principal, aqui, talvez seja se "a avaliação ética, baseada na análise de certos itens (apresentação do projeto; objetivo(s) da pesquisa; avaliação dos riscos e benefícios; comentários e considerações sobre a pesquisa; considerações sobre os termos de apresentação obrigatória; recomendações ${ }^{11}$, devidamente conferidos e compatibilizados) por parte dos membros de comitês de ética em pesquisa, assegura o tratamento ético na pesquisa". Como já explicitado, a avaliação ética, por si só, não assegura que a conduta de pesquisa seja ética,

\footnotetext{
${ }^{11}$ Estes são os tópicos constantes no parecer que um membro de comitê de ética em pesquisa deverá emitir em relação à avaliação ética de um projeto de pesquisa cadastrado na Plataforma Brasil.
}

de modo que outras formas de se fazer ética precisam continuar sendo implementadas. Talvez seja precisamente esse tipo de discussão que se tenha de levar às instâncias de pesquisa e de formação de novos pesquisadores. Isso porque as resoluções são limitadas, pretendem dar conta de uma padronização do mundo, o qual sempre escapa, sempre vaza por um lugar ou outro e aí é que se pensa que reside a ética coconstitutiva, como aquela que se aprende nas tradições de campo e que deve acontecer ao longo de toda a pesquisa concomitantemente ao regramento ético presente nas resoluções. Parafraseando Latour, elas visam a acondicionar o mundo em palavras. Como refere Débora Diniz (2015), uma das mais importantes vozes no cenário brasileiro acerca da ética em pesquisa:

Minha proposta [em relação aos princípios presentes nas regulamentações] não é implodir os sentidos da confidencialidade ou da privacidade para a pesquisa biomédica ou para outras formas de pesquisa social. Há grupos ou metodologias para quem a confidencialidade das informações é essencial para garantir direitos fundamentais, como é o caso das pesquisas que realizei sobre aborto entrevistando mulheres. No entanto, mesmo considerando-os como qualificadores ambíguos, assumo que há usos devidos e indevidos da informação pessoal - um uso indevido pode ser resultado do dever de confidencialidade sem prévia problematização de seus sentidos políticos e éticos para o grupo pesquisado (p. 2671). [Isso porque, como refere a autora, em relação à Zefinha, sujeito principal de seu texto] (...) o anonimato sobre a mulher abandonada há mais tempo em um manicômio judiciário no Brasil não protegeria aquela que vive esquecida, mas os poderes que permitiram sua existência (...). Minha tese é exatamente oposta à pressuposta pela Resolução CNS 466: nomear Zefinha é forçar a reconhecer o seu rosto, a identificá-la como a mulher abandonada há mais tempo em um manicômio judiciário no Brasil. A imagem de Zefinha é o que lhe resta - sua existência como velha dependente, abandonada em um hospital-presídio. Pobre, velha, analfabeta, nordestina, Zefinha não possui mais vínculos ou biografias fora do manicômio. Viveu como uma mulher anônima no regime de apartação - divulgar sua história é, portanto, uma forma de reconhecer sua existência como alguém cujos direitos foram amplamente violados. A responsabilidade que desejo assumir pela nomeação de Zefinha é esta: a de que testemunho a história de uma mulher abandonada em razão da loucura" (p. 2672 - grifos do autor) $)^{12}$.

Assim, como se pretende ter deixado claro com o excerto anterior, enfatiza-se que não se trata de se ser

\footnotetext{
${ }^{12}$ Sônia Kramer, bem antes das discussões relativas às resoluções 466/12 e $510 / 16$, empreendeu uma análise bastante similar a esta - posteriormente realizada por Diniz (2015) -, relativa à ética na pesquisa com crianças (vide KRAMER, 2002).
} 
contra a ética regulamentadora, mas de perceber que as resoluções ora em curso dão conta de um tipo de tratamento ético, atendem a algumas demandas de ordem ética no âmbito da pesquisa de circulação mundial, permitem padronizar (ou "achatar") a pesquisa em determinadas formatações, visam a proteger os participantes (e também pesquisadores e instituições) de determinadas formas. Mas não atendem às diferentes éticas - aquelas que se precisa levar em consideração nos fazeres cotidianos de pesquisa. De modo que, como enfatiza Diniz (op. cit.), nem sempre os princípios de anonimato e confidencialidade, por exemplo, assegurarão um tratamento ético, nem sempre protegerão os participantes. Portanto, cabe aos pesquisadores e formadores de outros pesquisadores, estudar, compreender e problematizar os preceitos éticos apresentados como universalizantes - ações raramente exploradas nos trabalhos das CHS. Com base nisso, propõe-se, ao menos no que tange à atuação como membro do Comitê de Ética da UFRGS - e sendo advindo da Faculdade de Educação -, que se opere no âmbito de uma ética coconstitutiva dos modos de se fazer pesquisa. A tarefa, antes que "temer" a ética assentada na revisão por pares, deve descrever detalhada e criticamente os modos de fazer, os quais não se resumem, como já foi destacado, a uma seção específica dos trabalhos, mas estão presentes ao longo de toda a pesquisa (da concepção à publicação e seus efeitos).

É Daniel Mato (2005), pesquisador latino-americano de Estudos Culturais, que, em um texto acerca da pesquisa em educação - sem, no entanto, mencionar a palavra "ética" -, tem-se empregado para melhor configurar o que se entende como uma ética coconstitutiva dos modos de se fazer pesquisa na Educação, ou, quiçá, nas CHS de um modo amplo. Nesse texto, Mato (2005) propõe alguns pontos que se devem seguir para que se possa inserir numa linha de investigação "conscientemente orientada por um propósito de contribuir para transformar as sociedades contemporâneas em termos de alcançar mais e melhor democracia e justiça social" (p. 159, destaque do autor).

As perguntas que se devem fazer quando se propõe uma investigação talvez sejam: A qual teoria deve-se filiar (qual é sua ética, sua política)? Como se pode agregar à dada comunidade interpretativa (frequentemente, sem conhecer o histórico de sua trajetória)? Como se assumem dados pressupostos ou não (aceitando como válidos princípios que, sequer, muitas vezes, foram discutidos)? O que se sabe acerca de suas histórias? Quais são as questões políticas (a agenda - explícita ou não) assumidas? O que e como se fala? A que(m) tal investigação serve? O que se busca com esta responder? Como se pode/deve tensionar dadas questões atinentes à pesquisa? O que esta permite que se veja (a partir de certos modos de ver)?
Como ele afirma, "formular problemas e perguntas de pesquisa, e consequentemente delinear projetos específicos, necessariamente têm consequências epistemológicas, teóricas e de método, isto é, nos modos específicos de produzir conhecimento" (MATO, 2005, p. 159). Daí as seguintes perguntas que se deve fazer ao serem formulados problemas e delineados projetos: que tipo de conhecimento gerar para que sejam úteis aos participantes de pesquisa? Como e para quem podem tais conhecimentos se tornar úteis? Como gerá-los de maneira ética e politicamente apropriada? Por que foram publicados? O que se espera com isso? Com quem se conversa ou a quem se endereça e com quais objetivos? Quais são os efeitos que se espera disso?

Essas são perguntas que remetem às assimetrias entre a produção e a disposição de conhecimentos por diversos atores sociais, pois "boa parte da investigação social sobre grupos em desvantagem acaba resultando mais útil àqueles outros atores sociais que desfrutam de situações de vantagem" (MATO, 2005, p.160). Isso porque "os resultados produzidos frequentemente só conduzem a comunicações escritas em linguagens especializadas e, em certas ocasiões, inclusive em idiomas desconhecidos pelos grupos humanos investigados". De modo que é preciso perguntar: como investigar "com" antes de produzir conhecimento "sobre" grupos humanos em desvantagem social e/ou política? Trata-se, como propõe Mato (2005, p.160-161), de investigar precisamente "sobre" os processos sociais que dizem respeito aos modos de construir/legitimar formas de vantagem social, econômica e/ou política à custa de outros atores sociais ou grupos humanos; de comunicar resultados das investigações de maneira direta a atores sociais afetados por essas assimetrias sociais, o que não conduz necessariamente a publicar nos formatos acadêmicos estabelecidos e, em algumas ocasiões, a nem sequer publicar, mas a comunicar resultados por outras vias; de comunicar resultados das investigações de forma que estimulem e facilitem aprendizagens por parte de profissionais, técnicos e/ou dirigentes sociais. O que não passa só pela publicação em formatos acadêmicos, mas também em outros formatos e meios, assim como pela docência ou em contextos extrauniversitários e pela internet.

No entanto, e tal como já referido anteriormente, além de seguir as proposições de Mato (na direção de uma linha de investigação conscientemente orientada por um propósito de contribuir para transformar as sociedades contemporâneas em termos de alcançar mais democracia e justiça social), o trabalho como pesquisadores e formadores de pesquisadores é também o de tensionar e produzir elementos críticos. Isso para que se possam construir procedimentos éticos que atendam não apenas 
aos quesitos necessários às avaliações por parte do sistema $\mathrm{CEP} / \mathrm{Conep}$, mas que sejam éticos em direção às perguntas aqui apresentadas. E estas remetem precisamente aos modos de se fazer pesquisa. Trata-se, segundo se entende, de um limite que dificilmente se aceita nos fazeres de pesquisa. Pode-se dizer, com base na experiência como avaliador de artigos, projetos, dissertações e tese, que, assim como muitos trabalhos não apresentam qualquer tratamento metodológico mais amplo, muitos projetos também não apresentam qualquer tratamento ético. $\mathrm{O}$ que atesta que frequentemente as questões de ordem ética sequer se constituem em questão importante para os pesquisadores.

Neste momento, tal como anunciado no início deste texto, tem-se uma resolução das ou para as CHS. Apesar dos possíveis engessamentos e resistências que se possam vislumbrar (que na linguagem CEP/Conep é visto como proteção aos participantes), a resolução está aberta, tal como procedeu Diniz (2015), a contestações, discordâncias e argumentações. Para isso, contudo, é preciso, minimamente, conhecer o que as resoluções estão dizendo sobre o que se deve (ou não) fazer.

Bonin, Ripoll e Santos (2015), bem como Santos e Karnopp (2017), vêm tentando proceder a uma crítica ao já referido principialismo ético que rege a bioética ou $a$ ética num sentido mais amplo, especialmente a partir das ideias de Petersen (2011) e Rose (2007). Petersen (op. cit.) refere-se ao caráter não monolítico da (bio)ética: não é uma coisa só, não pode ser vista como uma narrativamestra que baliza o bem e o mal, o certo e o errado, a Ciência (de matriz biomédica) e o "resto". A (bio)ética, segundo ele, é uma política - isto é, emerge como área organizada do conhecimento depois da Segunda Guerra Mundial, a partir de múltiplos esforços estadunidenses (vide STARK, 2012), e passa a se constituir em uma forma de regulação de comportamentos e condutas dos seres humanos nas mais variadas esferas da vida e em uma forma de "imperialismo"). O autor explica:

\footnotetext{
'Imperialismo' pode parecer uma palavra forte para descrever a difusão internacional e a crescente aplicação dos conceitos, princípios e práticas relacionadas à bioética. No entanto, se se concebe o Imperialismo como um sistema em que um país governa outros países, por vezes, sem o uso da força, para exercer poder sobre eles, então esta descrição pode não parecer muito rebuscada ou excessiva. Embora a força possa não ser utilizada, a suposição de que uma visão de mundo predominantemente estadunidense dada à bioética deve fornecer a base para a deliberação sobre as questões fundamentais da vida tem operado como uma forma de hegemonia ou de dominação cultural. Não é necessária nenhuma força ou violência, porque há um consenso quase universal de que a bioética pode e deve fornecer orientação sobre tais questões (PETERSEN, 2011, p. 6-7).
}

Tendo esclarecido isso, é preciso, então, dizer claramente que não se é (nos campos das Ciências Humanas e Sociais) contrário à Ética ou às diferentes éticas, mas questiona-se precisamente acerca do imperativo ético contemporâneo, assentado nas Ciências Biomédicas e em seu biocentrismo. Apesar da centralidade das ciências de chave "bio", consideradas como as mais capazes de explicar a "verdadeira natureza" humana, seguir os seus princípios como único modelo de possibilidade ética (construídos numa dada tradição de pesquisa) pode se revelar uma operação limitadora e reducionista. De modo amplo, pode-se dizer que é contra tal racionalidade reducionista que se tem debatido, de forma mais ou menos informada no que diz respeito às discussões que precederam e que continuam se sucedendo em relação à publicação da Resolução 466/12 e, mais especialmente, da Resolução 510/16.

Recorre-se novamente a Petersen (2013) para, agora, além da crítica ao imperialismo acadêmico-científico e ético, pontuar a principal crítica à adoção do principialismo - a versão mais influente da ética na pesquisa, caracterizada pelos princípios da autonomia, beneficência, não maleficência e justiça. Diz respeito ao "fato dele encaixar-se numa demanda institucional por uma lógica racional, oferecendo [assim] a expectativa da calculabilidade e da predicabilidade" (p. 1). Isso proveria as bases para uma 'economia moral global', permitindo e possibilitando a troca de ideias entre fronteiras nacionais e culturais. Em outras palavras, por meio de uma "ética comum", "universal", a produção dos conhecimentos poderia circular e fluir melhor não apenas pelos circuitos acadêmicos nacionais e internacionais, mas, igualmente, por aqueles do mercado de produtos e patentes, na direção daquilo que Rose (2007), apresentando e problematizando as políticas da vida no início do século XXI, chamou de "produção de biovalor" no âmbito da bioeconomia.

A ética, segundo esta crítica (do imperialismo e do principialismo - que devem ser vistos de modo articulado), seria mais uma commodity, um produto a ser "eticamente" consumido, pois "os produtos que não vierem com as garantias éticas apropriadas, notavelmente as seguranças quanto ao 'consentimento informado' dos doadores [no mercado do biovalor, no qual fluidos, células e tecidos corporais passaram a circular], ${ }^{13}$ não terão um caminho fácil pelos circuitos do biocapital" (ROSE, 2007, p. 30).

\footnotetext{
${ }^{13}$ Aliás, esse é um ponto recorrente em relação às críticas das CHS à matriz de origem biomédica das resoluções, qual seja, o fato de nas CHS não se lidar com fluidos, células ou tecidos. De qualquer modo, apesar das discussões recorrentes, há um certo consenso em admitir que as pesquisas das CHS também lidam com questões que, embora não sejam materiais (como fluidos, células ou tecidos), produzem efeitos simbólicos (ou psicológicos) importantes, tais como a rememoração de eventos desagradáveis ou temas relativos à intimidade dos participantes (vide GASTALDO e McKEVEER, 2002). E estes devem ser previstos, amenizados ou atendidos por profissionais especializados - no limite, o pesquisador deve se perguntar se, diante dos possíveis desconfortos (ou riscos, "na linguagem" CEP/ Conep) aí envolvidos, a pesquisa deve ou não ser realizada.
} 


\section{CONSIDERAÇõES FINAIS}

Considerando o que foi dito até aqui, cabe retomar algumas perguntas: representa-se uma comunidade de especialistas que compartilha de uma mesma visão de mundo, de um mesmo conjunto de conceitos que se articulam na busca de uma proposta comum de ética em pesquisa? Que conceitos de ciência e de ética em pesquisa são esses? Deve-se voltar, aqui, à guerra das duas culturas, de um lado as hard sciences e, de outro (e por oposição) as soft sciences?

Em relação à (bio)ética, e seu modelo de pesquisa, é preciso dizer que esta não é uma entidade monolítica, com uma única perspectiva e modo de investigação (PETERSEN, 2013). O termo (bio)ética é, de acordo com ele, mal definido, sendo frequentemente utilizado de modo intercambiável com 'ética médica', 'ética clínica' e 'ética de pesquisa', possibilitando, assim, que seja apropriado por vários grupos, frequentemente com diferentes agendas (PETERSEN, 2013, p. 2). Além disso, aqueles que empregam princípios (bio)éticos não se abrigam sob uma única identidade profissional, mas, antes, numa variedade de campos de especialidade, que podem incluir médicos, advogados, teólogos, filósofos, sociólogos, educadores/as, acadêmicas-feministas, pacientes-ativistas, entre outros, com diferentes objetivos, compreensões e trajetórias de (bio)ética.

Assim, retomando o mito de Babel, a guerra das duas culturas, o imperialismo ou colonização (bio)ética, e apesar da divisão fundante entre "as palavras e as coisas", tal como mostrou Foucault (1999), pode-se perguntar, diante das atuais configurações (bio)éticas no país: as CHS não poderiam contribuir "mais autonomamente", de dentro de suas próprias tradições de pesquisa, para a constituição de uma ética coconstitutiva dos modos de se fazer pesquisa? Pensa-se que sim, se souber se lidar com aquilo que se considera ser efeito de uma contingência histórica (a ameaça por uma política de retrocesso/backlash ao próprio sistema CEP-Conep, caracterizada, sobretudo, pela retirada dos direitos éticos aos participantes de pesquisa no Brasil). Além de saber também se lidar com a matriz imperialista da ciência (e consequentemente da ética), não apenas evitando as resoluções, mas resistindo a estas de modo crítico (o que pressupõe conhecê-las e "conversar" com elas - quiçá desfazendo-as - de dentro, como mostrou Diniz, 2015).

Isso posto, que questões éticas esse próprio movimento de resistência às resoluções regulamentadoras oferece para que se pensem as políticas de formação de novos pesquisadores, bem como as políticas de fomento em pesquisa no Brasil? Como a atual experiência dos comitês de ética em pesquisa (como o CEP da Universidade Federal do Rio Grande do Sul), que vêm, desde 2014, ampliando a sua composição e tornando-a mais equitativa entre membros das Ciências Humanas e Sociais e Biomédicas, pode possibilitar futuras formas de pensar e organizar a ética em pesquisa no país? Como (ou será que) a atual Resolução 510/16, que versa acerca das Especificidades das Ciências Humanas e Sociais, a despeito de sua trajetória (problemática ou problematizadora), poderá vir a se constituir num outro modo possível de se pensar as relações de poder que são parte da própria construção do conhecimento? Como se pode, desde aí, pensar em formas quiçá menos regulamentadoras e mais localizadas/“vivas"/ dinâmicas de se produzir conhecimento ante a crescente burocratização e complexificação dos modos de se fazer pesquisa num mundo em que o conhecimento (e os seus produtos: insumos, patentes, direitos autorais, etc.) precisa transitar com dadas "garantias éticas"?

Deve-se, como propõem Larrosa e Skliar (2001), aprender a viver juntos e a se comunicar ordenadamente? Deve-se conjurar os perigos de Babel e voltar a reunir os homens, não agora em torno de uma cidade, de uma torre, de um nome e de uma língua, mas a partir da diversidade bem ordenada e bem comunicada de diferentes cidades, diferentes torres, diferentes nomes e diferentes línguas (tal como um sistema de avaliação ética padronizado mundialmente)? Como eles mesmos pontuam, "tem-se a impressão de que a questão é administrar as diferenças, identificando-as, e tratar de integrar todos em um mundo inofensivamente plural e ao mesmo tempo burocrática e economicamente globalizado..." (LARROSA e SKLIAR, 2001, p. 11). Por fim, "lamentavelmente vivemos em Babel, como lamentavelmente fomos expulsos do Paraíso", e se nossa tarefa já não é mais reconquistar o Paraíso, ela é, nos dizem, "refazer a Unidade ou, pelo menos, administrar a Diversidade, mesmo que seja, isso sim, a partir do ponto de vista da vantagem do Capital e da ordem do Estado" (idem, p. 10). Assim, como não se vive no paraíso (aquilo que vagamente, aqui, chamou-se de uma "resolução dos sonhos"), como Babel é nossa ordem, como não se quer refazer ou reconstituir a unidade, como se vive num regime de vantagem do capital, resta, com base naquilo que se conseguir, procurar administrar as diversidades e, quiçá, desde aí, produzir algumas singularidades.

\section{REFERÊNCIAS}

APPADURAI, Arjun. O medo ao pequeno número - ensaio sobre a geografia da raiva. São Paulo: Iluminuras/Itaú Cultural, 2009.

BONIN, Iara T., RIPOLL, Daniela; SANTOS, Luís Henrique Sacchi. Ética, pesquisa e imagens de povos indígenas. Teias, v. 16, n. 42 , p. 106-125, jul./set. 2015.

DINIZ, Debora. Ela, Zefinha - o nome do abandono. Ciência e Saúde Coletiva, v. 20, n. 9. p. 2667-2674, 2015. 
FALUDI, Susan. Backlash: o contra-ataque na guerra não declarada contra as mulheres. Rio de Janeiro: Rocco, 2001.

FOUCAULT, Michel. As palavras e as coisas - uma arqueologia das ciências humanas. São Paulo: Martins Fontes, 1999.

GASTALDO, Denise; McKEEVER, Patricia. Investigación cualitativa. Intrínsecamente ética? In: MERCADO, J. et al. (Org.). Investigación cualitativa en salud en Iberoamérica: métodos, análisis y ética. Guadalajara: Universidad de Guadalajara/Universidad Autónoma de Nuevo León, 2002.

KRAMER, Sônia. Autoria e autorização: questões éticas na pesquisa com crianças. Cadernos de Pesquisa, n. 116, p. 41-59, jul. 2002.

LARROSA, Jorge; SKLIAR, Carlos. Habitantes de Babel políticas e poéticas da diferença. Belo Horizonte: Autêntica, 2001

LATOUR, Bruno. Jamais fomos modernos. Rio de Janeiro: Editora 34, 1994.

MATO, Daniel. Esboço para uma linha de investigação em cultura e transformações sociais em tempos de globalização. In: COSTA, Marisa Vorraber; BUJES, Maria Isabel E. (Org.). Caminhos investigativos III - riscos e possibilidades de pesquisas nas fronteiras. Rio de Janeiro: DP\&A, 2005. p. $155-177$.
PETERSEN, Alan. From bioethics to a sociology of bioknowledge. Social Science \& Medicine, p. 1-7, 2013. http:// dx.doi.org/10.1016/j.socscimed.2012.12.030

PETERSEN, Alan. The politics of bioethics. New York; London: Routledge, 2011.

RIBEIRO, Renato Janine. Novas fronteiras entre natureza e cultura. In: NOVAES, A. (Org.). O homem-máquina: a ciência manipula o corpo. São Paulo: Companhia das Letras, 2003. p. 15-36.

ROSE, Nikolas. The biopolitics of life itself - biomedicine, power, and subjectivity in the Twenty-First Century. Princeton, New Jersey, 2007.

ROSE, Nikolas. The human science in a biological age. Theory, Culture \& Society, v. 30, n. 1, p. 3-34, 2013.

SANTOS, Luís Henrique Sacchi dos; KARNOPP, Lodenir Becker (Org.). Ética e pesquisa em educação: questões e proposições às Ciências Humanas e Sociais: Porto Alegre: Editora da UFRGS, 2017.

STARK, Laura. Behind closed doors - IRBs and the making of ethical research. Chicago: The University of Chicago Press, 2012.

Recebido em 05-02-2017.

Aprovado em 30-04-2017. 